\title{
Cleft lip-retinopathy syndrome
}

INSERM

\section{Source}

INSERM. (1999). Orphanet: an online rare disease and orphan drug data base. Cleft lipretinopathy syndrome. ORPHA:1995

Cleft lip - retinopathy is an exceedingly rare association characterized by cleft lip and progressive retinopathy. 